Short Communication

\title{
Molecular cloning and expression analysis of Pleurodeles waltl complement component C3 under normal physiological conditions and environmental stresses
}

\author{
Nathan Guéguinou, Cécile Huin-Schohn, Nassima Ouzren-Zarhloul, Stéphanie Ghislin, \\ Jean-Pol Frippiat* \\ Lorraine University, Faculty of Medicine, Stress Immunity Pathogens Laboratory, EA7300, 9 Avenue de la Forêt de Haye, F-54500 Vandœuvre-lès-Nancy, France
}

\section{A R T I C L E I N F O}

\section{Article history:}

Received 26 March 2014

Revised 16 April 2014

Accepted 17 April 2014

Available online 24 April 2014

\section{Keywords}

Pleurodeles walt

Urodele amphibian

Complement component

Environment

Stress

\begin{abstract}
A B S T R A C T
C3 is a component of the complement system that plays a central role in immunity, development and tissue regeneration. In this study, we isolated the C 3 cDNA of the Iberian ribbed newt Pleurodeles waltl. This cDNA encodes a 1637 amino acid protein with an estimated molecular mass of $212.5 \mathrm{kDa}$. The deduced amino acid sequence showed that $P$. waltl $\mathrm{C} 3$ contains all the conserved domains known to be critical for C3 function. Quantitative real-time PCR (qRT-PCR) demonstrated that under normal physiological conditions, $P$. waltl C3 mRNA is expressed early during development because it is likely required for neurulation. Then, its expression increased as the immune system developed. In adults, the liver is the richest source of $\mathrm{C} 3$, though other tissues can also contribute. Further analysis of $\mathrm{C} 3$ expression demonstrated that $\mathrm{C} 3$ transcription increased when $P$. walt larvae were exposed to $\mathrm{pH}$ or temperature stress, suggesting that environmental modifications might affect this animal's defenses against pathogens.
\end{abstract}

(c) 2014 Elsevier Ltd. All rights reserved.

\section{Introduction}

The complement system is a critical component of innate immunity and is key in the protection against infections. This system involves a family of proteins that are mainly synthetized by the liver (Walport, 2001a,b), though lower levels can be produced by other cell types. Complement activation can be achieved in the extracellular space through three pathways (classical, lectins or alternative) and intracellularly via a cathepsin-dependent mechanism (Liszewski et al., 2013).

All complement activation pathways converge at the level of C3, the key component, which is processed into activation fragments C3a and C3b (Collard et al., 2000), with the assembly of C5 convertase and the further release of the C5a and C5b fragments. C3a and $\mathrm{C} 5 \mathrm{a}$ are anaphylatoxins that exert a plethora of pro-inflammatory and immunoregulatory functions (Guo and Ward, 2005). In addition to their pro-inflammatory properties, these molecules regulate antigen-presenting cell functions and adaptive immune responses (Klos et al., 2009). Indeed, C3a and C5a have been shown to modulate the expression levels of MHC class II and costimulatory molecules on dendritic cells (Strainic et al., 2008; Weaver

\footnotetext{
* Corresponding author. Tel.: +33 383683723 .

E-mail address: jean-pol.frippiat@univ-lorraine.fr (J.-P. Frippiat).
}

et al., 2010). C5b initiates the terminal phase of complement activation, i.e., the formation of the membrane-attack complex (MAC) in association with the C6, C7, C8 and 1-18 molecules of C9, which leads to the formation of pores in pathogen membranes (Bhakdi and Tranum-Jensen, 1991; Esser, 1991).

In addition to their immunological functions, complement molecules are also involved in early vertebrate development. Indeed, the expression of complement molecules at the gastrula/ early neurula stage and organ-specific expression patterns during organogenesis were observed in Xenopus laevis (McLin et al., 2008). Furthermore, a recent study showed that Xenopus neural crest cells are coattracted via the complement fragment C3a and its receptor C3aR (Carmona-Fontaine et al., 2011).

Complement also becomes activated during tissue injury and remodeling. Complement proteins have been shown to be involved in tissue and organ regeneration (Del Rio-Tsonis et al., 1998; Kimura et al., 2003; Mastellos et al., 2013). Distinct complementtriggered pathways have been shown to modulate critical responses that promote tissue reprogramming, pattern formation and regeneration across phylogenesis (Mastellos et al., 2013).

Despite these critical immunologic and nonimmunologic functions, complement molecules have only been considered in the context of regeneration studies in urodele amphibians (Del Rio-Tsonis et al., 1998; Kimura et al., 2003). Furthermore, no 
complete urodele mRNA complement sequence is available in the GenBank or EMBL databases, and, to our knowledge, no study has analyzed the expression of these important molecules in these species in response to environmental changes. Consequently, we characterized the C3 cDNA of the urodele amphibian Pleurodeles waltl, studied its tissue distribution and expression during embryonic development and the effects of $\mathrm{pH}$ and temperature changes on its expression.

\section{Materials and methods}

\subsection{Animals and RNA extraction}

$P$. waltl (embryos, larvae and adults) were reared in our animal facilities at $20^{\circ} \mathrm{C}$ under controlled conditions approved by the French Ministry of Agriculture and Fisheries (agreement DDSV54/ SPA/07/130) and treated in accordance with national legislation and the European Communities Council Directive on the Protection of Animals Used for Experimental and Other Scientific Purposes 86/ $609 /$ EEC. To avoid as much as possible potential contamination, embryos and larvae were reared in Evian spring water (http:// www.evian.com/files/evian\%202013\%20AWQR\%20CALIF\%20ENG.pdf).

Developmental stages were defined according to Gallien and Durocher (1957). Nine embryos or larvae were randomly chosen for each developmental stage studied and homogenized in TRIzol reagent (Invitrogen, Carlsbad, CA, USA) for RNA extraction. Total RNA was also isolated from the thymus of stage 44 (36-day-old) larvae and from various adult tissues (blood, brain, heart, intestine, kidney, liver, lung, spleen and testis).

\section{2. $\mathrm{pH}$ and temperature challenge}

To assess the effects of environmental changes on $P$. walt $\mathrm{C} 3$ expression, larvae at stage 36-37 of development (14 days after laying, 2 days after hatching) were placed for $3 \mathrm{~h}$ in aquaria in which the $\mathrm{pH}$ was increased to 9 (initial $\mathrm{pH}$ was 7.2 ) or for $24 \mathrm{~h}$ in aquaria in which the temperature was 7 or $10^{\circ} \mathrm{C}$ above the normal rearing temperature $\left(20^{\circ} \mathrm{C}\right)$. No larvae died during these two treatments. After $3 \mathrm{~h}$ at $\mathrm{pH} 9$ or $24 \mathrm{~h}$ at 27 or $30^{\circ} \mathrm{C}$, the larvae were homogenized in TRIzol reagent for RNA extraction, except for one group that was sacrificed $14 \mathrm{~h}$ after the $27^{\circ} \mathrm{C}$ heat shock. For each treatment, larvae of the same developmental stage reared under standard conditions were used as controls.

\subsection{Cloning and sequencing of $P$. waltl C3 cDNA}

One microgram of liver RNA was reverse transcribed using random primers and MMLV reverse transcriptase (Invitrogen, Carlsbad, CA, USA) in a final volume of $20 \mu \mathrm{l}$. Primers were designed in conserved regions identified by aligning C3 mRNA sequences from Homo sapiens (EMBL accession number BC15 0179), Gallus gallus (AAA64694), Xenopus tropicalis (XM_0029 40050), Naja naja (AAA49385), Lethenteron camtschaticum (AB37 7282), Oncorhynchus mykiss (L24433) and Oryzias latipes (AB025 575). A first PCR reaction was performed with the C3-PW-For and C3-PW-Rev primers (Supplementary Table 1) using $10 \mathrm{ng}$ of liver cDNA and Goldstar Taq polymerase (Eurogentec, Seraing, Belgium). The PCR program was as follows: $5 \mathrm{~min}$ at $94^{\circ} \mathrm{C}$, then 40 cycles of $30 \mathrm{~s}$ at $94{ }^{\circ} \mathrm{C}, 30 \mathrm{~s}$ at $55^{\circ} \mathrm{C}$ and $1 \mathrm{~min} 30 \mathrm{~s}$ at $72{ }^{\circ} \mathrm{C}$ and finally $3 \mathrm{~min}$ at $72^{\circ} \mathrm{C}$. A single PCR product of $1316 \mathrm{bp}$ was obtained, cloned in the pGEMT $^{\circledR}$-Easy vector (Promega, Madison, WI, USA) and sequenced. Next, specific primers (C3-PW-GSP1 and C3-PW-GSP2) and nested primers (C3-PW-NGSP1 and C3-PW-NGSP2) (Supplementary Table 1) were designed from the obtained sequence to perform 3'- and 5'-RACE using the BD SMART RACE cDNA Amplification kit (Clontech, Mountain View, USA) and MMLV reverse transcriptase (Invitrogen). The RACE products were cloned, sequenced and assembled to obtain the full-length $P$. waltl C3 cDNA.

\subsection{Sequence analysis}

Translation was performed using the Transeq program available on the portal for bioinformatic analyses of the Pasteur Institute (http://mobyle.pasteur.fr). Protein domains were determined via a BLAST analysis (http://blast.ncbi.nlm.nih.gov/). Sequence alignments were performed using ClustalW (http://www.ebi.ac.uk/ Tools/msa/clustalw2/) and a phylogenetic tree was constructed by NJ method supported with 1000 bootstrap replications using the MEGA6 software (http://www.megasoftware.net/).

\subsection{Real-time PCR}

Primers specific for $P$. walt C3, HSF1, HSP70, HSP90 and 4 housekeeping genes (GAPDH, $\alpha$-actin, TAFII and mitochondrial 16S RNA) were designed using the Genscript software (http://genscript.com/ssl-bin/app/primer) (Supplementary Table 1) in different exons to ensure that they could not hybridize to potential traces of genomic DNA. The specificity of each primer pair was tested using a BLAST search through the U.S. National Center for Biotechnology Information (Bethesda, MD, USA). Real-time PCR was performed using the Mesa Green qPCR Master Mix (Eurogentec) and a Mastercycler ${ }^{\circledR}$ realplex $^{2}$ real-time PCR machine (Eppendorf, Hamburg, Germany). The cycling protocol was as follows: $3 \mathrm{~min}$ at $95^{\circ} \mathrm{C}$, followed by 40 cycles of $15 \mathrm{~s}$ at $94^{\circ} \mathrm{C}$ and $30 \mathrm{~s}$ at the annealing temperature indicated in Supplementary Table 1. Standard curves were produced to ensure that the amplification efficiencies were similar and in the range of 95-105\%. Melting curves were processed to check the quality of the PCR and verify the amplicon's melting temperature. Each PCR was performed in triplicate and repeated at least two times. Data were analyzed using the relative Pfaffl model (Pfaffl, 2001). Relative expression levels were calculated by comparison to the 4 housekeeping genes using the GeNorm software and Vandesompele's methodology (Vandesompele et al., 2002).

\subsection{Western blotting}

Proteins were prepared by lysing a pool of 3 larvae in lysis buffer containing $1 \%$ triton X-100, $150 \mathrm{mM} \mathrm{NaCl}, 10 \%$ glycerol, 0.1\% SDS, 50 mM HEPES, 50 mM NaF, 1 mM NaVO3, 2 mM EDTA. Samples of $50 \mu \mathrm{g}$ of protein were heated at $97^{\circ} \mathrm{C}$ for $5 \mathrm{~min}$, separated by SDS-PAGE and electrotransferred to a PVDF membrane (Amersham, Buckinghamshire, UK). Immunodetection was performed using antibodies against HSP70 (1:200) from Millipore (Billerica, MA, USA), HSP90 (1:5000) from Stressgen (Ann Arbor, MI, USA) or $\alpha$-actin $(1: 20,000)$ from BD Transduction Laboratories (San Diego, CA, USA). Western blot results were quantified by densitometry using a Fusion Fx7 imaging system (Vilber Lourmat, Marne-la-Vallée, France) and expressions were normalized to $\alpha$-actin.

\subsection{Statistical analysis}

Statistical analyses were performed using SPSS 13.0 (SPSS Inc., Chicago, IL, USA). Outlier values were determined by a boxplot of each group studied. When normality and homogeneity of variances were ascertained, Student $t$ test analyses were performed to establish 2-group comparisons. Otherwise, Mann-Whitney tests were used for 2-group comparisons. Values of $p<0.05$ and $<0.10$ were 

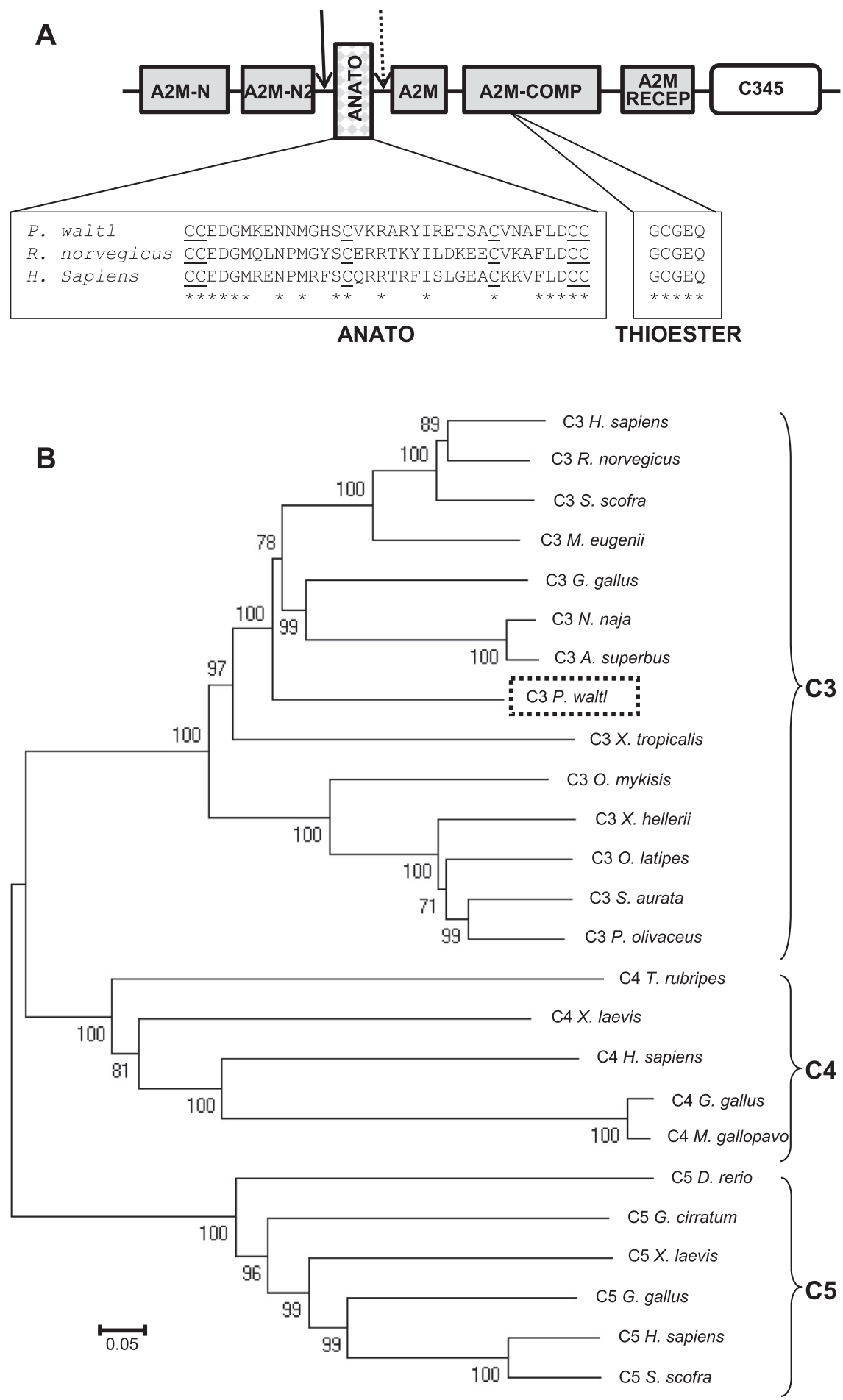

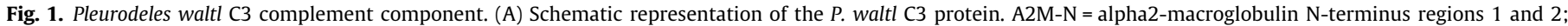

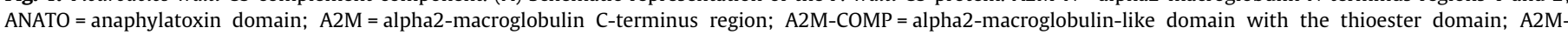

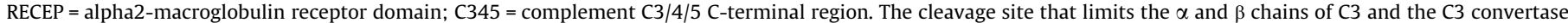

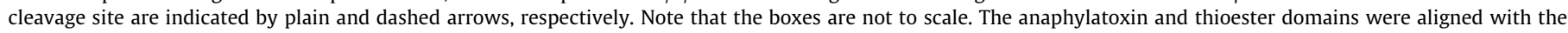

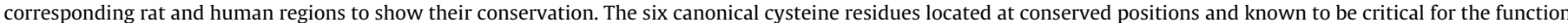

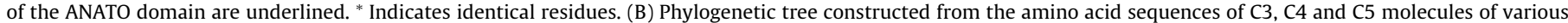

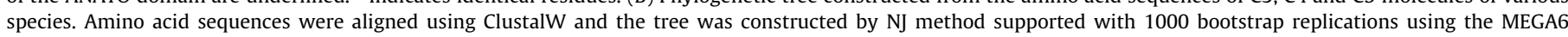

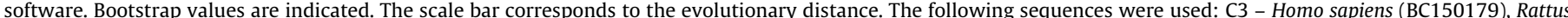

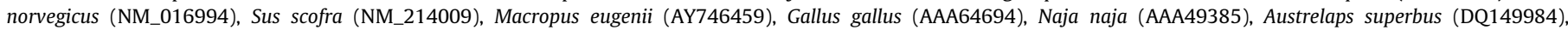

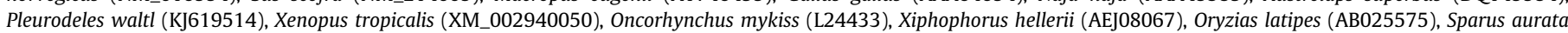

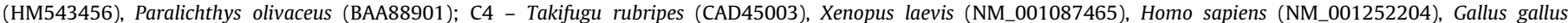

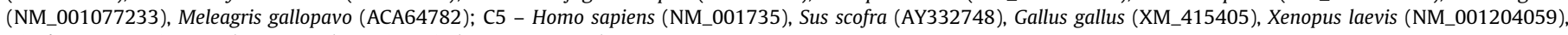
Ginglymostoma cirratum (EU797190), Danio rerio (XP_001919226). 
A Developmental stages

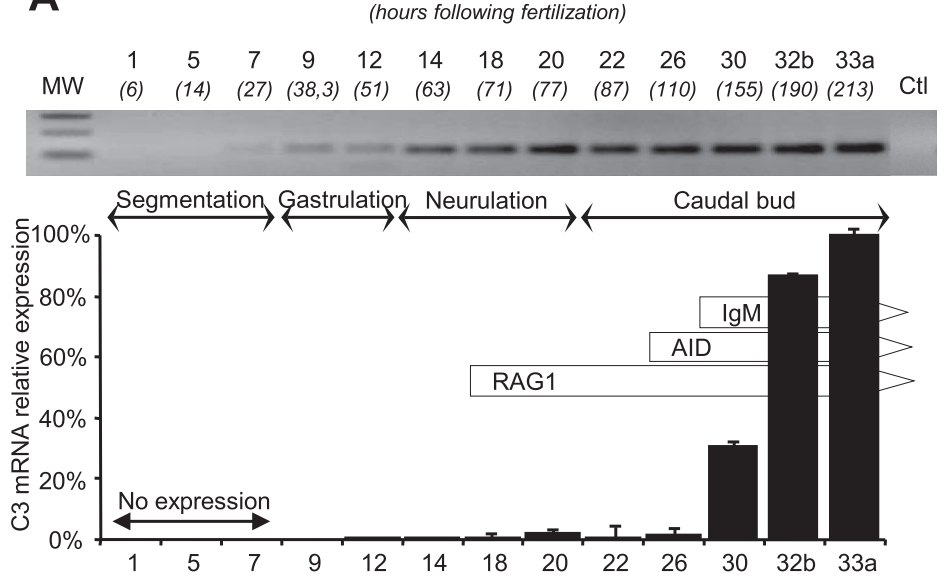

\section{B}

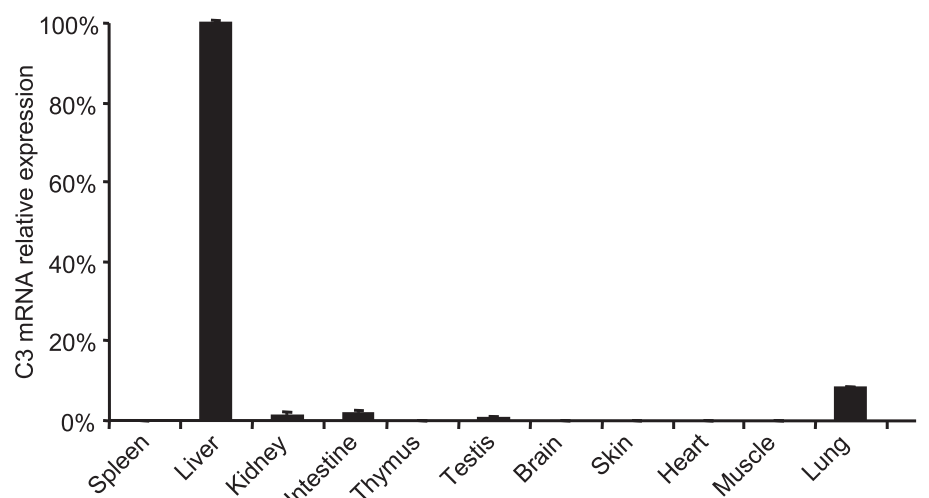

E

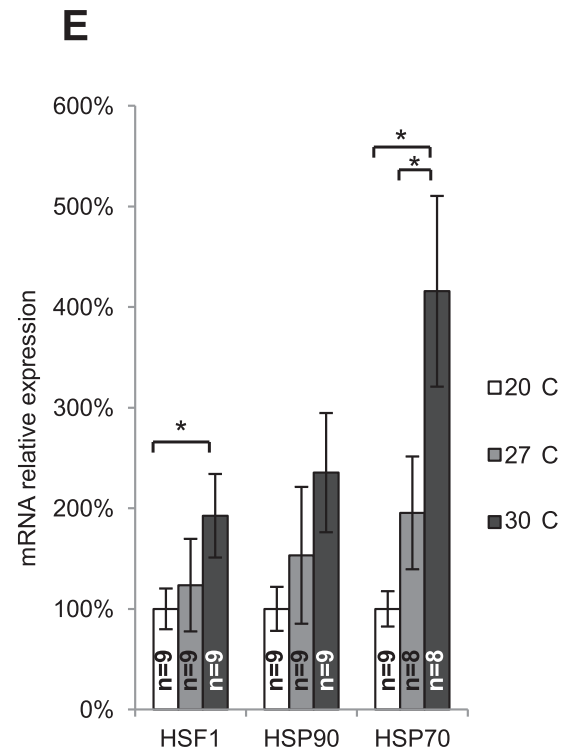

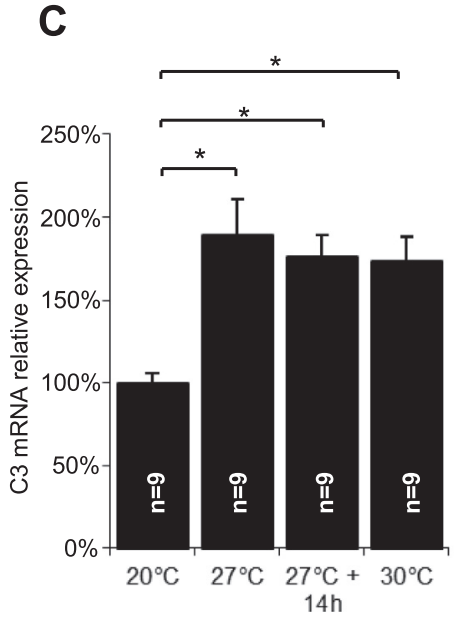

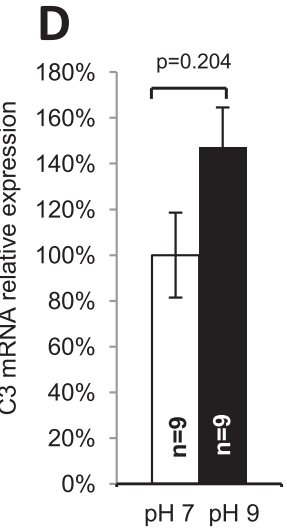

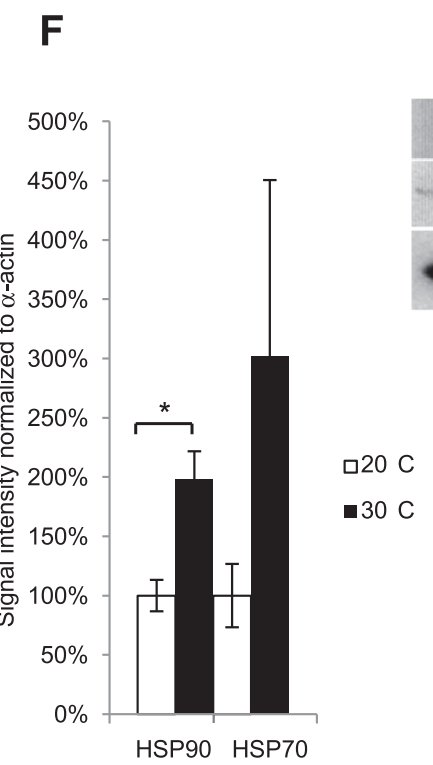

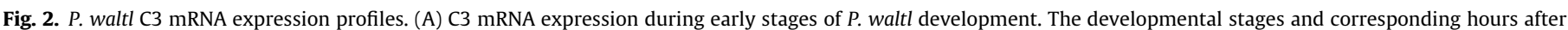

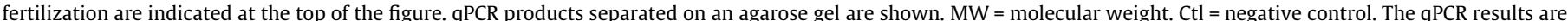

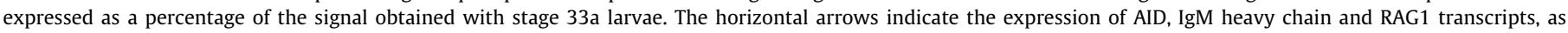

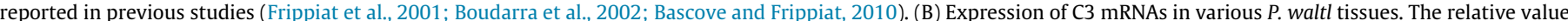

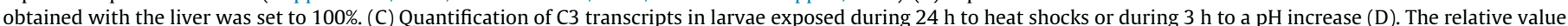

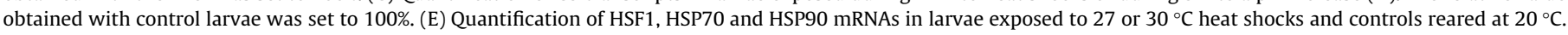

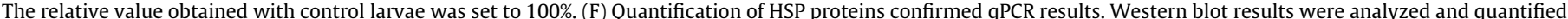

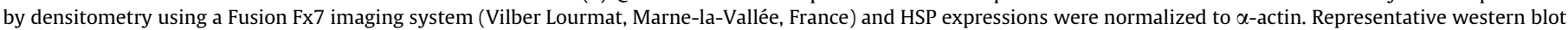

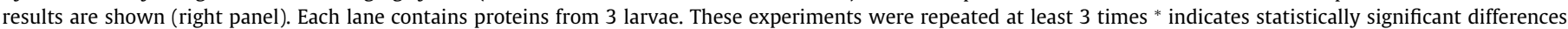
$(p<0.05)$. For each panel, the values represent the means \pm SEM. 
selected to indicate significance and trend, respectively. All the results are shown as means \pm SEM.

\section{Results and discussion}

\subsection{Characteristics of P. walt C3 cDNA}

Overlapping $5^{\prime}$ - and $3^{\prime}$-RACE PCR products were assembled to obtain the full-length $P$. waltl C3 cDNA sequence, which was deposited in GenBank (accession number KJ619514). This cDNA has an open reading frame of 4911 bp and encodes a 1637 amino acid protein with an estimated molecular mass of $212.5 \mathrm{kDa}$. In contrast to Lambris et al. (1995) who described an X. laevis alternative C3 transcript that lacks many of the ligand binding sites, no splice variant was detected during this study.

Alignment of the predicted $P$. waltl C3 amino acid sequence with $\mathrm{C} 3$ sequences from other species showed that this molecule possesses all the domains typical of $\mathrm{C} 3$ complement molecules. Indeed, our sequence possesses five $\alpha 2$-macroglobulin domains (C3, C4 and C5 are members of the $\alpha 2$-macroglobulin family), one anaphylatoxin domain responsible for inflammatory activities and the complement C3/4/5 C-terminal region (Fig. 1A). Moreover, $P$. waltl C3 possesses the highly conserved cleavage site RXXR (RRRR for $P$. waltl) at residues 662-665 upstream of the anaphylatoxin domain, which defines the limit between the $\alpha$ and $\beta$ chains of C3 (plain vertical arrow in Fig. 1A), as in all currently known C3 sequences. The anaphylatoxin domain is located at the $\mathrm{N}$-terminus of the $\alpha$ chain and contains all the residues known to be critical for its functions (Castillo et al., 2009; Qi et al., 2011). The conserved cleavage site recognized by $\mathrm{C} 3$ convertase is also present in the predicted C3 sequence (LFLARSEVEE, cleavage between the $\mathrm{R}$ and $\mathrm{S}$ residues, as indicated by the dashed vertical arrow in Fig. 1A) at residues 737-746, leading to a predicted $P$. walt $\mathrm{C} 3$ a fragment of 76 amino acids ( 78 amino acids in human and mouse) containing the anaphylatoxin domain. Finally, the thioester motif GCGEQ, allowing the covalent binding of $\mathrm{C} 3$ to the target cell membrane (Law and Dodds, 1997), is present at residues 1003-1007 in the predicted $P$. waltl C3 amino acid sequence.

\subsection{Phylogenetic analysis}

To confirm that we isolated the C3 cDNA of $P$. waltl, we built a phylogenetic tree with C3, C4 and C5 sequences (Fig. 1B). This tree shows that the sequence identified in $P$. waltl clusters with $C 3$ proteins and not with C4 or C5 sequences. P. waltl C3 presents between $53 \%$ and $61 \%$ similarity with the C3 proteins used to construct this tree, the highest similarities (61\%) being found with amino acid sequences from Austrelaps superbus and N. naja.

\subsection{Expression profile during embryonic development and tissue distribution}

The expression patterns of $\mathrm{C} 3$ during embryogenesis and in $P$. waltl tissues were analyzed by qRT-PCR. As shown in Fig. 2A, the first expression of $\mathrm{C} 3$ was detected at stage 7 and remained low during gastrulation. C3 transcription increased during neurulation (from stage 14 to 20 ) and was stronger after stage 26 when immunoglobulin heavy chain transcripts are expressed. Thus C3 mRNA expression preceded the expression of other immunological genes (RAG1, AID and IgM heavy chains) (Frippiat et al., 2001; Boudarra et al., 2002; Bascove and Frippiat, 2010). Similarly, C3 transcripts were detected at the gastrula/early neurula stages in $X$. laevis (McLin et al., 2008) and were shown to be required for the proper migration of neural crest cells (Carmona-Fontaine et al., 2011). Thus, as in X. laevis, C3 is likely expressed at early developmental stages in $P$. walt because it is required for neurulation. Fig. 2B shows that, as in other vertebrates, that the liver is the major source of complement C3 expression. Some lower levels of transcription could be detected in the lungs, intestine, kidney and testis.

Taken together, the sequence and expression features suggest that $P$. waltl C3 functions in a similar way to the C3 molecules of other animals.

\subsection{Expression after a $\mathrm{pH}$ or temperature challenge}

Environmental parameters affect the physiological responses of aquatic animals (Bascove et al., 2011; Qi et al., 2011; Frippiat, 2013; Huin-Schohn et al., 2013; Schenten et al., 2013). Consequently, we investigated the expression profile of $\mathrm{C} 3$ in $P$. waltl larvae exposed to temperature or $\mathrm{pH}$ stress. Our data reveal a significant increase in $\mathrm{C} 3 \mathrm{mRNA}$ expression following exposure to two heat shocks ( 27 or $30^{\circ} \mathrm{C}$ ) for $24 \mathrm{~h}$ (Fig. 2C) and an increase, which was not statistically significant, in C3 mRNA expression following exposure to $\mathrm{pH} 9$ for $3 \mathrm{~h}$ (Fig. 2D). We also noted that the temperature-induced increase in transcription was rather stable because the same level of C3 mRNA was still observed $14 \mathrm{~h}$ after the end of the $27^{\circ} \mathrm{C}$ heat shock. These responses could be mounted by $P$. waltl larvae to neutralize harmful free radicals generated by stress treatments. Indeed, previous studies have shown that $\mathrm{pH}$ and temperature challenges can cause oxidative damage and the generation of ROS in ark shell, Pacific white shrimp, Mediterranean mussel and orange-spotted grouper (Frenzilli et al., 2001; Wang et al., 2009; An and Choi, 2010; Qi et al., 2011). Furthermore, it has been shown that complement activation plays an important role in the inflammatory process after oxidative stress (Collard et al., 1999). There is increasing evidence that ROS activate the complement system and $\mathrm{C} 3$ is thought to provide protection against oxidative stress (Collard et al., 1999, 2000; Hart et al., 2004). Another possibility is that danger signals, such as HSP, that are induced by heat shock (Fig. 2E) up-regulate C3 expression, as shown in photodynamic therapy-treated tumors (Stott and Korbelik, 2007). An inspection of know C3 promoter sequences (human, mouse and rat) using the Match and TFSEARCH programs (available at http://www.gene-regulation.com/cgi-bin/pub/programs/match/bin/match.cgi and http://www.cbrc.jp/research/db/ TFSEARCH.html) confirmed the presence of heat shock protein binding sites (data not shown). However, verifying this hypothesis will require the cloning and analysis of the $P$. waltl $\mathrm{C} 3$ promoter to determine whether it also contains heat shock response element binding sites.

In conclusion, we cloned the C 3 cDNA from $P$. waltl for the first time and showed the conservation of this molecule in urodeles. This molecule is expressed early during development because it is likely required for neurulation. Then, its expression increased as the immune system developed. As in other vertebrates, the liver is the richest source of $\mathrm{C} 3$ in adults. Furthermore, we observed increased C3 mRNA levels after the exposure to temperature or $\mathrm{pH}$ increases, suggesting an activation of the immune system of this species.

\section{Acknowledgments}

We thank Oussama El-Baraka for his technical assistance, the French National Space Agency (CNES), the French National Research Agency (ANR grant NT09-632666), the French Ministry of Higher Education and Research, the Lorraine University and the Lorraine area for their financial support. N.G. and C.H.-S. were supported by Ph.D. and postdoctoral fellowships, respectively, from the National Research Fund of Luxembourg. 


\section{Appendix A. Supplementary data}

Supplementary data associated with this article can be found, in the online version, at http://dx.doi.org/10.1016/j.dci.2014.04.011.

\section{References}

An, M.I., Choi, C.Y., 2010. Activity of antioxidant enzymes and physiological responses in ark shell, Scapharca broughtonii, exposed to thermal and osmotic stress: effects on hemolymph and biochemical parameters. Comp. Biochem. Physiol. B Biochem. Mol. Biol. 155 (1), 34-42.

Bascove, M., Frippiat, J.-P., 2010. Molecular characterization of Pleurodeles walt activation-induced cytidine deaminase. Mol. Immunol. 47 (7-8), 1640-1649.

Bascove, M., Guéguinou, N., Schaerlinger, B., Gauquelin-Koch, G., Frippiat, J.-P., 2011. Decrease in antibody somatic hypermutation frequency under extreme, extended spaceflight conditions. FASEB J. 25 (9), 2947-2955.

Bhakdi, S., Tranum-Jensen, J., 1991. Complement lysis: a hole is a hole. Immunol. Today 12 (9), 318-320.

Boudarra, N., Frippiat, C., Dournon, C., Frippiat, J.-P., 2002. An alternative internal splicing site defines new Ikaros isoforms in Pleurodeles waltl. Dev. Comp. Immunol. 26 (7), 659-673.

Carmona-Fontaine, C., Theveneau, E., Tzekou, A., Tada, M., Woods, M., Page, K.M., Parsons, M., Lambris, J.D., Mayor, R., 2011. Complement fragment C3a controls mutual cell attraction during collective cell migration. Dev. Cell 21 (6), 10261037.

Castillo, M.G., Goodson, M.S., McFall-Ngai, M., 2009. Identification and molecular characterization of a complement C3 molecule in a lophotrochozoan, the Hawaiian bobtail squid Euprymna scolopes. Dev. Comp. Immunol. 33 (1), 69-76.

Collard, C.D., Lekowski, R., Jordan, J.E., Agah, A., Stahl, G.L., 1999. Complement activation following oxidative stress. Mol. Immunol. 36 (13-14), 941-948.

Collard, C.D., Väkevä, A., Morrissey, M.A., Agah, A., Rollins, S.A., Reenstra, W.R. Buras, J.A., Meri, S., Stahl, G.L., 2000. Complement activation after oxidative stress: role of the lectin complement pathway. Am. J. Pathol. 156 (5), 15491556.

Del Rio-Tsonis, K., Tsonis, P.A., Zarkadis, I.K., Tsagas, A.G., Lambris, J.D., 1998. Expression of the third component of complement, C3, in regenerating limb blastema cells of urodeles. J. Immunol. 161 (12), 6819-6824.

Esser, A.F., 1991. Big MAC attack: complement proteins cause leaky patches. Immunol. Today 12 (9), 316-318.

Frenzilli, G., Nigro, M., Scarcelli, V., Gorbi, S., Regoli, F., 2001. DNA integrity and tota oxyradical scavenging capacity in the Mediterranean mussel, Mytilus galloprovincialis: a field study in a highly eutrophicated coastal lagoon. Aquat. Toxicol. 53 (1), 19-32.

Frippiat, C., Kremarik, P., Ropars, A., Dournon, C., Frippiat, J.-P., 2001. The recombination-activating gene 1 of Pleurodeles waltl (urodele amphibian) is transcribed in lymphoid tissues and in the central nervous system. Immunogenetics 52 (3-4), 264-275.

Frippiat, J.-P., 2013. Contribution of the urodele amphibian Pleurodeles walt to the analysis of spaceflight-associated immune system deregulation. Mol. Immunol. 56 (4), 434-441.

Gallien, L., Durocher, M., 1957. Table chronologique du développement chez Pleurodeles walt Michah. Bull. Biol. Fr. Belg. 91, 97-114.

Guo, R.F., Ward, P.A., 2005. Role of c5a in inflammatory responses. Annu. Rev. Immunol. 23, 821-852.

Hart, M.L., Walsh, M.C., Stahl, G.L., 2004. Initiation of complement activation following oxidative stress. In vitro and in vivo observations. Mol. Immunol. 41 (2-3), 165-171.
Huin-Schohn, C., Guéguinou, N., Schenten, V., Bascove, M., Gauquelin-Koch, G., Baatout, S., Tschirhart, E., Frippiat, J.-P., 2013. Gravity changes during animal development affect IgM heavy-chain transcription and probably lymphopoiesis. FASEB J. 27 (1), 333-341.

Kimura, Y., Madhavan, M., Call, M.K., Santiago, W., Tsonis, P.A. Lambris, J.D., Del RioTsonis, K., 2003. Expression of complement 3 and complement 5 in newt limb and lens regeneration. J. Immunol. 170 (5), 2331-2339.

Klos, A., Tenner, A.J., Johswich, K.O., Ager, R.R., Reis, E.S., Köhl, J., 2009. The role of the anaphylatoxins in health and disease. Mol. Immunol. 46 (14), 2753-2766.

Lambris, J.D., Pappas, J., Mavroidis, M., Wang, Y., Manzone, H., Schwager, J., Du Pasquier, L., Silibovsky, R., Swager, J., 1995. The third component of Xenopus complement: cDNA cloning, structural and functional analysis, and evidence for an alternate C3 transcript. Eur. J. Immunol. 25 (2), 572-578.

Law, S.K., Dodds, A.W., 1997. The internal thioester and the covalent binding properties of the complement proteins C3 and C4. Protein Sci. 6 (2), 263-274.

Liszewski, M.K., Kolev, M., Le Friec, G., Leung, M., Bertram, P.G., Fara, A.F., Subias, M., Pickering, M.C., Drouet, C., Meri, S., Arstila, T.P., Pekkarinen, P.T., Ma, M., Cope, A., Reinheckel, T., Rodriguez de Cordoba, S., Afzali, B., Atkinson, J.P., Kemper, C., 2013. Intracellular complement activation sustains $\mathrm{T}$ cell homeostasis and mediates effector differentiation. Immunity 39 (6), 1143-1157.

Mastellos, D.C., Deangelis, R.A., Lambris, J.D., 2013. Complement-triggered pathways orchestrate regenerative responses throughout phylogenesis. Semin. Immunol. 25 (1), 29-38.

McLin, V.A., Hu, C.H., Shah, R., Jamrich, M., 2008. Expression of complement components coincides with early patterning and organogenesis in Xenopus laevis. Int. J. Dev. Biol. 52 (8), 1123-1133.

Pfaffl, M.W., 2001. A new mathematical model for relative quantification in realtime RT-PCR. Nucleic Acids Res. 29 (9), e45.

Qi, Z.H., Liu, Y.F., Wang, W.N., Wu, X., Xin, Y., Lu, Y.F., Wang, A.L., 2011. Molecular characterization and functional analysis of a complement C3 molecule in the orange-spotted grouper (Epinephelus coioides). Fish Shellfish Immunol. 31 (6), 1284-1290.

Schenten, V., Guéguinou, N., Baatout, S., Frippiat, J.-P., 2013. Modulation of Pleurodeles walt DNA polymerase mu expression by extreme conditions encountered during spaceflight. PLoS ONE 8 (7), e69647.

Stott, B., Korbelik, M., 2007. Activation of complement C3, C5, and C9 genes in tumors treated by photodynamic therapy. Cancer Immunol. Immunother. 56 (5), 649-658.

Strainic, M.G., Liu, J., Huang, D., An, F., Lalli, P.N., Muqim, N., Shapiro, V.S., Dubyak, G.R., Heeger, P.S., Medof, M.E., 2008. Locally produced complement fragments C5a and C3a provide both costimulatory and survival signals to naive CD4 ${ }^{+} \mathrm{T}$ cells. Immunity 28 (3), 425-435.

Vandesompele, J., De Preter, K., Pattyn, F., Poppe, B., Van Roy, N., De Paepe, A., Speleman, F., 2002. Accurate normalization of real-time quantitative RT-PCR data by geometric averaging of multiple internal control genes. Genome Biol. 3 (7), RESEARCH0034.

Walport, M.J., 2001a. Complement. First of two parts. N. Engl. J. Med. 344 (14), 1058-1066.

Walport, M.J., 2001b. Complement. Second of two parts. N. Engl. J. Med. 344 (15), $1140-1144$.

Wang, W.N., Zhou, J., Wang, P., Tian, T.T., Zheng, Y., Liu, Y., Mai, W.J., Wang, A.L. 2009. Oxidative stress, DNA damage and antioxidant enzyme gene expression in the Pacific white shrimp, Litopenaeus vannamei when exposed to acute $\mathrm{pH}$ stress. Comp. Biochem. Physiol. C Toxicol. Pharmacol. 150 (4), 428-435.

Weaver Jr., D.J., Reis, E.S., Pandey, M.K., Köhl, G., Harris, N., Gerard, C., Köhl, J., 2010. C5a receptor-deficient dendritic cells promote induction of Treg and Th17 cells, Eur. J. Immunol. 40 (3), 710-721. 